\title{
The Impact of Chronic Pelvic Pain in Women
}

\author{
Adriana Peterson Mariano Salata Romão ${ }^{1}$, Ricardo Gorayeb ${ }^{2}$, Gustavo Salata Romão ${ }^{3}$, \\ Omero Benedicto Poli-Neto ${ }^{1,4}$, Antonio Alberto Nogueira ${ }^{5}$
}

\begin{abstract}
${ }^{1}$ Department of Gynecology and Obstetrics, School of Medicine of Ribeirão Preto, University of São Paulo, Ribeirão Preto, SP, Brazil; ${ }^{2}$ Department of Neurosciences and Behavioral Sciences, School of Medicine of Ribeirão Preto, University of São Paulo, Ribeirão Preto, SP, Brazil; ${ }^{3}$ Federal University of São Carlos, SP, Brazil; ${ }^{4}$ Department the Surgery and Anatomy, University Hospital, Faculty of Medicine of Ribeirão Preto, University of São Paulo, Ribeirão Preto, SP, Brazil; ${ }^{5}$ Department of the Surgery and Anatomy, University Hospital, Faculty of Medicine of Ribeirão Preto, University of São Paulo, Ribeirão Preto, SP, Brazil.

Email: adrianapeterson@uol.com.br
\end{abstract}

Received August $6^{\text {th }}, 2013$; revised September $3^{\text {rd }}, 2013$; accepted September $23^{\text {rd }}, 2013$

Copyright (C) 2013 Adriana Peterson Mariano Salata Romão et al. This is an open access article distributed under the Creative Commons Attribution License, which permits unrestricted use, distribution, and reproduction in any medium, provided the original work is properly cited.

\begin{abstract}
Chronic pelvic pain (CPP) is a prevalent condition with a significant impact on the personal, social, professional and marital life of women. It is a complex condition that may have no specific causal diagnosis or may be associated with multiple diagnoses, frequently involving treatment failure. The definition of health care strategies fundamentally depends on the way women live with this condition. Thus, the objective of the present study is to learn how women with CPP experience their diagnosis and the meaning they attribute to it. A qualitative study was conducted by interviewing a focus group of 11 women. The content of the interviews was recorded and fully transcribed, and the speeches were interpreted by Bardin's content analysis. The topics most frequently dealt with in the interview were diagnosis, beginning of pain, worsening and improving factors, marital and interpersonal relationships, interference with daily activities, association with emotional aspects, and perspectives for the future. It could be perceived how much these women need to be better heard and how much the association between psychic and physical questions must be visualized by the professionals who provide care for them. The approach used by professionals from different areas, when properly structured, can minimize the problem of the division of a sick person into separate parts. Psychological care is very important, especially in relation to the discovery of more effective strategies for living with pain.
\end{abstract}

Keywords: Lived Experience; Chronic Pelvic Pain; Qualitative Method; Women’s Health

\section{Introduction}

Chronic pelvic pain (CPP) is characterized by continuous or intermittent pain located on the anterior abdominal wall at the level of the navel or below, lasting at least 6 months, not exclusively related to the menstrual period or to sexual intercourse, and sufficiently severe to cause functional disability [1]. Although the prevalence of CPP in developing countries is unknown, it is estimated to be higher in Brazil than in developed countries, with a direct impact on the marital, social, professional and sexual life of the patients [2-5].

Studies have shown that, after 3 years of treatment with different modalities such as physiotherapy, psychology, pharmacology or surgery, only $20 \%$ of the women with CPP recover [6,7]. This inefficiency of CPP treatment seems to be responsible in part for the dissatisfaction and frustration of the patients and of the health professionals and for the conflicts between them.

In addition, even though various countries have adopted the biopsychosocial model and the psychosomatic approach, modern medicine is still widely based on the biomedical model [8], which is currently also on the basis of medical training in Brazil. This model separates the physical aspects of health from the psychological ones.

However, the current attitude is that the psychosocial dimensions should be reintegrated into health care and practice in order to construct a biopsychosocial model [9]. The treatment of CPP is an important challenge for the health team since it requires a combination of pharmacological and non-pharmacological interventions associated with several types of invasive procedures. CPP seldom reflects a separate pathological process, normally consisting of a combination of psychological $[10,11]$, social and biological factors, thus essentially requiring an interdisciplinary approach involving doctors, physio- 
therapists and psychologists, among others, for a more effective treatment of women with CPP [12-14].

Within the context of CPP in particular, knowing and interpreting the meanings that women attribute to the problems they experience can permit the professionals to expand their understanding of the problem in order to contribute to the promotion of more effective interventions through individualized health care and an integrated health care service [9]. Due to the complexity of this disease, multidisciplinary teams can make a significant contribution within this context, with psychologists considering the emotional aspects and helping the patients to deal with the context in which the pain is triggered and physiotherapists dealing with body aspects and muscle changes.

Contributions such as improved quality of the professional-patient-family-institution relationship, greater adhesion to the treatments proposed, the understanding of the feelings, ideas and behaviors of the patients and their relatives and even those of the professional health team would be possible by attributing the proper value to the meanings of the life experiences of the individuals involved in the health-sickness process [15]. However, despite the relevant role of this type of approach on the health scenario, almost all studies focusing on CPP are quantitative. Thus, in the present study, we opted for a qualitative approach in order to deepen the experience of these women and the meaning they attribute to chronic pain.

\section{Methods}

Patients: Thirty-six women with a diagnosis of CPP were invited to participate in the study. The patients had been studied in a previous investigation and were followed up at a Gynecology Outpatient Clinic of a University
Hospital in the interior of Brazil. Of the 36 patients invited, 11 came to the clinic on the scheduled day. The remaining 25 patients were not available or their telephone number was wrong or they could not be contacted. Thus, the 11 patients were divided into two groups of six and five patients, respectively (Table 1). A meeting was held with each group. The inclusion criteria were: a diagnosis of CPP and more than 18 years of age. Exclusion criteria were: a history of psychiatric diroders (psychosis) preceding the disease and presence of other chronic diseases such as systemic arterial hypertension, diabetes mellitus, cancer, or being pregnant.

Instrument: The instrument used for data collection was a focus group interview held in a single session. This technique is a particularly appropriate resource for quailtative investigations in which the participants will feel more stimulated to express their opinions than when they are interviewed separately, since they also interact with one another or with the group moderator [16].

Procedures: The group meetings were held in a room specifically selected for the present study. The chairs were arranged in a circle so that there would be visual contact among all participants. Two tape recorders were placed on two small tables on opposite sides in order to guarantee that all speeches would be recorded. At the beginning of the interview the researcher explained the objectives of the study and all subjects gave written informed consent to participate. The researcher used a guiding question (how is it to live with CPP?) that served as the theme for conducting the group session. It was emphasized that there would be no right or wrong replies and that the opinion of each participant would be of fundamental importance. The interview lasted one hour and thirty minutes.

Table 1. Socio-economic-relational profile.

\begin{tabular}{|c|c|c|c|c|c|c|c|}
\hline Ident. & Age & Religion & Profession & Education & Family Income & Time of relationship & No. of Children \\
\hline W1 & 28 & Catholic & Seamstress & Complete high school & $\$ 524,70^{1}$ & 1 and a half year & 01 \\
\hline W2 & 30 & Spiritualist & Seller & Complete high school & $\$ 655,88$ & 7 years & 05 \\
\hline W3 & 28 & Evangelical & Maid & Complete high school & $\$ 212,62$ & 4 years & 04 \\
\hline W4 & 44 & Catholic & Housewife & Complete high school & $\$ 655,88$ & 22 years & 02 \\
\hline W5 & 43 & Evangelical & Artisan & Complete secondary school & $\$ 524,70$ & 27 years & 03 \\
\hline W6 & 37 & Spiritualist & Hairdresser & Incomplete secondary school & $\$ 437,25$ & 21 years & 02 \\
\hline W7 & 36 & Evangelical & Poultry farm assistant & Complete elementary school & $\$ 524,70$ & 12 years & 03 \\
\hline W8 & 34 & Catholic & Vector control agent & Complete high school & $\$ 874,50$ & 16 years & 03 \\
\hline W9 & 38 & Catholic & Housewife & Complete elementary school & $\$ 189,33$ & 3 years & 01 stepson \\
\hline W11 & 44 & Catholic & Companion of older people & Complete elementary school & $\$ 306,70$ & 24 years & 04 \\
\hline
\end{tabular}

*Amount regarding the current minimum (in dollars) wage at the time of interview. 
The interview was conducted by the researcher, who acted as an agent facilitating and promoting group conversation so that opinions and ideas would emerge without the pretense of reaching a consensus. This methodological resource permitted the interviewees to talk freely about the process of falling ill and about their daily relations, values and transformations perceived after the onset of symptoms. During the interview, the researcher sought to keep the group involved and managed it in such a way as to preserve its flexibility and dyna- mism. The objective of her interventions was to facilitate conversation and to provide space so that all women would talk.

Data analysis: The option for the analysis of this study was content analysis as suggested by Bardin [17] according to the following steps: Pre-analysis (reading of the material/formulation of hypotheses/pre-categorization); Exploration of the material (exhaustive reading of the material/definition of meaning unit/classification of the categories), and Analysis and interpretation of the results (definition of the thematic units of the study and treatment of the results by performing inferences and interpreting the aggregate contents).

\section{Results}

Mean patient age was 35.7 years (range: 28 to 44 years). Six women had 9 years of schooling (54.6\%), two had 11 years (18.2\%) and three had five years (27.3\%). Regarding their profession, two had no type of remuneration and nine had remunerated activities. The mean number of children was 2.7 and the time of relationship was 13.4 years. Monthly family income ranged from R $\$ 500.00$ to $\mathrm{R} \$ 2,000.00$ (U\$ 226.04 to U\$ 904.15).

The thematic units most frequently approached during the focus group interview were: diagnosis, relationship, interference of CPP with daily activities, association of pain with emotional aspects, and perspectives for the future. These topics will be approached in more detail in the Discussion.

\section{Discussion}

\subsection{Diagnosis}

In the present study, the lack of explanations about the symptoms seems to cause expectations regarding the effective diagnosis.

W2: I told my mother I would prefer if there were a pair of scissors or a piece of gauze that you could remove and it would get better, it would be a solution, something you could remove, but who can remove this? There is no way of removing it, because I don't know if there is a cure, is there?

The primordial wish of these women to find the cause of their pain is a prevalent topic in the various studies on this subject [18-22]. There is a constant search among these women for the primary diagnosis of pain. This necessity is associated with the wish to legitimize the symptom so as to permit treatment and the elimination of more serious diagnoses such as cancer [23-27]. One of the justifications of this search is that falling ill represents a threat to the physical and psychological integrity of an individual, with a consequent attempt to give a meaning to the experience of falling ill in order to render it more understandable and less threatening within the social universe of the affected person [28].

\subsection{Relationships}

The women consider the participation of their partners to be important, although some of them stated that they do not have this type of help or understanding.

W2: My husband doesn't understand it, sometimes he thinks that I am having an affair, and says he wants to meet someone new... I told him he could believe whatever he wants to, I am in pain and I am not doing it, I don't have to do anything that causes pain.

Another important condition is the feeling of obligetion to have sex. Sexual difficulties are frequent in the life of women with CPP [29-33], with their speeches showing that they feel the obligation to have an active sex life. Therefore, they decide "to make believe that they have no pain", thus actually intensifying the pain process.

W2: I feel cornered, then I say: I will have to sleep with him. I wait for a few minutes to see if it gets back to normal, and then it's like I said, it comes to this. Then, last week I said, what am I doing? I am not going to keep doing this, no way. Since it is not going to get better if I do it, I decided to change this routine, and I got into a crisis again...

Concern with discredit and impairment of interpersonal relations.

W2: Sometimes you say it to your partner, who is your husband, and he think you are whining.

The conditions regarding the social roles of the women are aggravated by economic, social and cultural difficultties. In addition, there is the naturally accepted inequality between men and women which permit to consider the health problems of women to be "women's stuff", which therefore does not deserve treatment.

W3: Sometimes my husband says... you're too obnoxious... I bet you are in those days...

The concepts and interpretation given by western medicine to pains of "nonspecific" cause located in the pelvic region affect the care provided for women who suffer with CPP, which is based on a lot of prejudice. These women are seen as "super-hysterical", and "whin- 
ing” [34].

W2: He says my name should be Sorrowful Mary, because everything hurts, my feet, my head, my stomach, and sometimes I think: I am really going crazy, I think I should be hospitalized. I am the only one in pain, so it is uncomfortable, like she said.

\subsection{Daily Activities}

The changes described are not limited to physical problems, but also involve impairment of social, professional, marital and maternal life, limiting the skills of women in fulfilling their roles.

W3: I don't work because I can't, it's a sort of pain that crushes you, you can't take it, I really don't think I am capable of working.

W2: I work because I am self-employed, but there are days you just feel like wilting, and when you get home you have to lie down...

Other situations such as losing a job, divorce, limitation of social contacts and reduced practice of physical activities owing to pain are common among these women.

The speeches of these women reveal their difficulties in performing their household tasks and even in taking care of their children.

W8: Because I got used to this pain, it bothers me, of course it hurts- it hurts a lot, and it irritates me. I have always been very patient with my daughters, and I am no longer patient, you know? I just warn them: "When I am in pain you had better not talk to me, because I cannot control myself'. It's terrible. And if I have to go out I can't even dress myself properly, because I feel there is something wrong, the pain.

\subsection{Perspectives for the Future}

In their speeches, the women interviewed in the present study demonstrated distrust of care and despair regarding the improvement of pain.

W2: There was a time when I got better, then I stopped coming here for the medication (painkiller injections) and the rest got worse.

W9: I received a letter saying I had to come a long time ago. Then I said: "I am not going anymore, I am not going to continue because it isn't getting any better, I went there to treat something and now it is getting worse, all of this came up, I am not going back there." My husband told me today: "Go there, you are in pain."

In general, women with CPP have a long history of pain, marked psychic suffering, physical involvement, difficulty to work and distrust of treatment. These conditions may favor non-adhesion, prolong the pain and suffering, cause impairment of physical and psychic functionality, and cause deterioration of quality of life [35].

\subsection{Emotional Aspects}

Two problems are more commonly observed when dealing with chronic pain: patients with injuries that are not always resolved and often lead to the permancence of symptoms, and patients who have pain symptoms but often show no injuries that might justify the pain. These facts often lead the professionals to consider that these patients "have nothing", ignoring the specificities of chronic disease, with the possibility that a woman will have anatomical changes which, however, do not justify the painful signs and symptoms [36].

W9: The last time I came here I told him I felt like it was burning around my navel, with a stinging sensation. And he said: "Ah, but I think it is nothing".

Emotional changes associated with pain include symptoms of mental and physical fatigue, periods of depresssion, crying episodes, sleeping problems, impatience, and irritability. These women report that they feel unable to plan their daily life owing to the constant imminence of pain [19].

Women with CPP are known to have marked psychic suffering, especially in relation to depression. Some of the speeches of the women in the study group permitted us to perceive the association of pain and depression.

W2: I have had depression since my adolescence. I have the impression it was not treated well, not solved. I started to take a lot of medications when I was still very young, and now since my girl was born I can't take the medication. If I take the medication now I pass out, I can't understand where it came from, and the medication can't help either.

Other women reported that they often felt the wish to end their own life, demonstrating the presence of despair in addition to depressive symptoms.

W3: The other day I told my husband: if this pain goes on for five more days I am going to put a rope around my neck and jump. Another day I told my son I was going to find a hole to put my head in. And later I thought to myself "Oh my God, I can't believe what I just said to my son".

The life conditions experienced by these women occasionally lead to life styles focused pain and on failed strategies of pain control, possibly contributing to the persistence of the problem. In addition, the presence of secondary gains may be another factor responsible for an "increased pain behavior" and for ineffective coping strategies $[37,38]$. In a study on women living with endometriosis, Matta [39] showed that, despite the difficulty of living with the disease, this group reported secondary gains due to it, i.e., mobilization of affection, family attention and proximity of one's mother and caregivers.

In a speech related to this topic, M3 reports that she 
only feels better when she lies down and mainly when her relatives do what she asks for. It can be seen that, in a way, the presence of pain favors gains for her and this can be associated with the maintenance of pain.

W3: Lying down is really good, it does not relieve the pain, but makes me feel better. I say I cannot spend my whole life in bed, but if I just give orders I am like a queen, and I don't feel anything, but if I do something (laughter)... Because that's the way it is, people do things for me, and I even improved. They thought it was due to the painkiller but it wasn't, it was the resting, resting makes it better... So I lie down.

Studies have demonstrated that women with CPP have developed various coping strategies in order to overcome the barriers imposed by pain, changing their routine and reorienting their daily actions. In order to reduce pain they rely on self-medication, on the ingestion of high doses of the medications prescribed by the doctors and adopt cultural practices passed on from generation to generation such as the use of home remedies (herbs), warm compresses, drinking wine and hot beverages, massage, and local heat, among others. Similarly, within the context of daily activities are distraction techniques such as watching TV, listening to music or interacting with children [19].

Regarding coping, although the context is directed $a$ priori towards depressive symptoms and difficulties in visualizing future possibilities, some options can be discussed based on the testimony provided by the patients.

W4: Now, fifteen days before it I take a homeopathic remedy. Some months I don't take it, I control myself. Sometimes he says things to me and I just take a deep breath and keep quiet, because I know that after my period I am going to be a different person. It took me many years to learn that, but I learned to control myself. I learned to control it and I take the medicine when I see I am going to need it, and then I just keep controlling it.

\section{Final Considerations}

The objective of the present study was to learn in a more profound manner the lived experience of these women regarding CPP. The various aspects identified provide evidence of the multiple needs of these women. The data obtained can be used to propose an approach based on the concept of multidisciplinary. Qualitative studies dealing with different central topics and other perspectives are important for planning the goals of clinical services. The present study also demonstrated the importance of psychological care, primarily about more effective strategies for living with pain, stress and depression. Techniques based on cognitive-behavioral therapy have been extensively used to treat psychological disorders such as stress related to health problems. These techniques intend to change cognitive distortions and non-functional beliefs so that the patients will be better able to obtain social support and to engage in pleasurable activities, preventing diseases and reducing the pain threshold.

\section{REFERENCES}

[1] ACOG., "Practice Bulletin Chronic Pelvic Pain,” Obstetrics \& Gynecology, Vol. 103, 2004, pp. 589-605.

[2] P. Latthe, et al., "WHO Systematic Review of Prevalence of Chronic Pelvic Pain: A Neglected Reproductive Health Morbidity,” BMC Public Health, Vol. 6, 2006, p. 177. http://dx.doi.org/10.1186/1471-2458-6-177

[3] V. Grace and K. Zondervan, "Chronic Pelvic Pain in Women in New Zealand: Comparative Well-Being, Comorbidity, and Impact on Work and Other Activities," Health Care for Women International, Vol. 27, No. 7, 2006, pp. 585-599.

http://dx.doi.org/10.1080/07399330600803725

[4] A. Romao, R. Gorayeb, G. S. Romao, O. B. Poli-Neto and A. A. Nogueira, "Impact of Chronic Pelvic Pain on Female Sexual Function,” International Journal of Clinical Medicine, Vol. 4, 2013, pp. 178-182. http://dx.doi.org/10.4236/ijcm.2013.43031

[5] G. P. Silva, et al., "High Prevalence of Chronic Pelvic Pain in Women in Ribeirao Preto, Brazil and Direct Association with Abdominal Surgery," Clinics (Sao Paulo), Vol. 66, No. 8, 2011, pp. 1307-1312.

[6] P. T. Weijenborg, et al., "Clinical Course of Chronic Pelvic Pain in Women,” Pain, Vol. 132, No. 1, 2007, pp. S117-S123. http://dx.doi.org/10.1016/j.pain.2007.06.020

[7] P. T. Weijenborg, et al., "Predictors of Outcome in a Cohort of Women with Chronic Pelvic Pain: A Follow-Up Study,” European Journal of Pain, Vol. 13, No. 7, 2009, pp. 769-775.

http://dx.doi.org/10.1016/j.ejpain.2008.09.002

[8] L. McCollum and T. Pincus, "A Biopsychosocial Model to Complement a Biomedical Model: Patient Questionnaire Data and Socioeconomic Status Usually Are More Significant than Laboratory Tests and Imaging Studies in Prognosis of Rheumatoid Arthritis," Rheumatic Disease Clinics of North America, Vol. 35, No. 4, 2009, pp. 699712. http://dx.doi.org/10.1016/j.rdc.2009.10.003

[9] P. P. Souza, et al., "Qualitative Research as the Basis for a Biopsychosocial Approach to Women with Chronic Pelvic Pain,” Journal of Psychosomatic Obstetrics \& Gynecology, Vol. 32, No. 4, 2011, pp. 165-172.

http://dx.doi.org/10.3109/0167482X.2011.607523

[10] A. P. Romao, et al., "High Levels of Anxiety and Depression Have a Negative Effect on Quality of Life of Women with Chronic Pelvic Pain,” International Journal of Clinical Practice, Vol. 63, No. 5, 2009, pp. 707-711. http://dx.doi.org/10.1111/j.1742-1241.2009.02034.x

[11] A. P. Romao, et al., "Chronic Pelvic Pain: Multifactorial Influences," Journal of Evaluation in Clinical Practice, Vol. 17, No. 6, 2011, pp. 1137-1139. http://dx.doi.org/10.1111/j.1365-2753.2010.01485.x

[12] J. Gunter, "Chronic Pelvic Pain: An Integrated Approach to Diagnosis and Treatment," Obstetrical \& Gyneco- 
logical Survey, Vol. 58, No. 9, 2003, pp. 615-623. http://dx.doi.org/10.1097/01.OGX.0000083225.90017.01

[13] M. B. F. Gurian, A. M. de Souza, A. P. M. da Silva, Montenegro, M. L. L. de Souza Montenegro, O. B. P. Neto, F. J. C. dos Reis, A. A. Nogueira1 and J. C. Rosa e Silva, "Chronic Pelvic Pain of Musculoskeletal Cause in Women,” Expert Review of Obstetrics \& Gynecology, Vol. 7, No. 2, 2012, pp. 149-157. http://dx.doi.org/10.1586/eog.12.13

[14] M. L. L. M.-V. de Souza Montenegro, E. Cristine, C. dos Reis, F. José, R. e Silva, J. César, A. A. Nogueira, A. A. Nogueira, P. Neto and O. Benedicto, "Thiele Massage as a Therapeutic Option for Women with Chronic Pelvic Pain Caused by Tenderness of Pelvic Floor Muscles," Journal of Evaluation in Clinical Practice, 2010, pp. 981982.

[15] E. R., Turato, "Qualitative and Quantitative Methods in Health: Definitions, Differences and Research Subjects," Revista de Saúde Pública, Vol. 39, No. 3, 2005, pp. 507514. http://dx.doi.org/10.1590/S0034-89102005000300025

[16] J. Kitzinger, "Qualitative Research, Introducing Focus Groups,” BMJ, Vol. 311, No. 7000, 1995, pp. 299-302. http://dx.doi.org/10.1136/bmj.311.7000.299

[17] L. Bardin, “Análise de Conteúdo,” Lisboa, P.U.d. France, 1977.

[18] V. Grace, "Problems Women Patients Experience in the Medical Encounter for Chronic Pelvic Pain: A New Zealand Study," Health Care for Women International, Vol. 16, No. 6, 1995, pp. 509-519. http://dx.doi.org/10.1080/07399339509516206

[19] J. B. Zadinsky, "Experiences of Women with Chronic Pelvic Pain," Health Care for Women International, Vol. 17, No. 3, 1996, pp. 223-232.

[20] J. Z. Moore and S. Kennedy, “'People Sometimes React Funny if They're Not Told Enough': Women's Views about the Risks of Diagnostic Laparoscopy," Health Expect, Vol. 5, No. 4, 2002, pp. 302-309. http://dx.doi.org/10.1046/j.1369-6513.2002.00192.x

[21] J. Price, G. Farmer, J. Harris, T. Hope, S. Kennedy and R. Mayou, "Attitudes of Women with Chronic Pelvic Pain to the Gynecological Consultation: A Qualitative Study,” BJOG, Vol. 113, No. 4, 2006, pp. 446-452. http://dx.doi.org/10.1111/j.1471-0528.2006.00862.x

[22] L. L. McGowan, F. Creed and C. A. Chew-Graham, "How Do You Explain a Pain That Can't Be Seen? The Narratives of Women with Chronic Pelvic Pain and Their Disengagement with the Diagnostic Cycle," British Journal of Health Psychology, Vol. 12, No. 2, 2007, pp. 261274.

[23] V. M. Grace, "Problems Women Patients Experience in the Medical Encounter for Chronic Pelvic Pain: A New Zealand Study," Health Care for Women International, Vol. 16, No. 6, 1995, pp. 509-519. http://dx.doi.org/10.1080/07399339509516206

[24] J. K. Zadinsky and J. S. Boyle, "Experiences of Women with Chronic Pelvic Pain,” Health Care for Women International, Vol. 17, No. 3, 1996, pp. 223-232. http://dx.doi.org/10.1080/07399339609516237
[25] C. Savidge, et al., "Women's Perspectives on Their Experiences of Chronic Pelvic Pain and Medical Care," Journal of Health Psychology, Vol. 3, No. 1, 1998, pp. 103-116. http://dx.doi.org/10.1177/135910539800300108

[26] J. Price, et al., "Attitudes of Women with Chronic Pelvic Pain to the Gynaecological Consultation: A Qualitative Study,” BJOG, Vol. 113, No. 4, 2006, pp. 446-452. http://dx.doi.org/10.1111/j.1471-0528.2006.00862.x

[27] V. M. Grace and S. MacBride-Stewart, “Women Get This”: Gendered Meanings of Chronic Pelvic Pain,” Health (London), Vol. 11, No. 1, 2007, pp. 47-67. http://dx.doi.org/10.1177/1363459307070803

[28] G. A. Cardoso, "Social Representations of Seropositivity and Treatment Adherence," Ciência e Saúde Coletiva, Vol. 10, No. 1, 2005, pp. 151-162. http://dx.doi.org/10.1590/S1413-81232005000100022

[29] N. W. Ambler, A. C. de C Williams, P. Hill, R. Gunary, and G. Cratchley, "Sexual Difficulties of Chronic Pain Patients,” Clinical Journal of Pain, Vol. 17, No. 2, 2001, pp. $138-145$. http://dx.doi.org/10.1097/00002508-200106000-00006

[30] T. N. Monga, G. Tan, H. J. Ostermann, U. Monga and M. Grabois, "Sexuality and Sexual Adjustment of Patients with Chronic Pain,” Disability and Rehabilitation, Vol. 20, No. 9, 1998, pp. 317-329. http://dx.doi.org/10.3109/09638289809166089

[31] B. D. Reed, H. K. Haefner, M. R. Punch, R. S. Roth, D. W. Gorenflo and B. W. Gillespie, "Psychosocial and Sexual Functioning in Women with Vulvodynia and Chronic Pelvic Pain,” Journal of Reproductive Medicine, Vol. 45, 2000, pp. 624-632.

[32] F. F. Verit, A. Verit and E. Yeni, "The Prevalence of Sexual Dysfunction and Associated Risk Factors in Womem with Chronic Pelvic Pain: Cross-Sectional Study," Archives of Gynecology and Obstetrics, Vol. 274, No. 5, 2006, pp. 297-302.

http://dx.doi.org/10.1007/s00404-006-0178-3

[33] T. M. Tripoli, et al., "Evaluation of Quality of Life and Sexual Satisfaction in Women Suffering from Chronic Pelvic Pain with or without Endometriosis,” The Journal of Sexual Medicine, Vol. 8, No. 2, 2011, pp. 497-503. http://dx.doi.org/10.1111/j.1743-6109.2010.01976.x

[34] L. Silva, “Dor Pélvica Crônica: Desafio ao Dualismo,” In FIOCRUZ, Rio de Janeiro, 2005. http://dx.doi.org/10.1590/S0004-282X2003000300017

[35] G. P. Kurita, “Adesão ao Tratamento da dor Crônica: Estudo de Variáveis Demográficas, Terapêuticas e Psicossociais,” Arq Neuro Psiquiatr, Vol. 61, No. 2b, 2003, pp. 416-425.

[36] C. E. Baptista and S. Fortes, "Grupoterapia e Dor Crônica,” In: J. A. B. Figueiró, G. Angelotti and C. A. de M. Pimenta, Dor \& Saúde Mental, Atheneu, São Paulo, 2005.

[37] L. O. Seger, "Psicologia Aplicada à Disfunção da Articulação Temporomandibular," In: Psicologia e Odontologia: Uma Abordagem Integradora, Santos, São Paulo, 2002, pp. 203-242. http://dx.doi.org/10.1037/0735-7028.33.2.176 
[38] J. Albino, “A Psychologist's Guide to Oral Diseases and Disorders and Their Treatment," Professional Psychology, Research and Practice, Vol. 33, No. 2, 2002, pp. 176182.
[39] A. M. Matta, “A Qualitative Analysis of Living with Endometriosis,” Psicologia, Saúde \& Doenças, Vol. 7, No. 1, 2006, pp. 57-72. 